\title{
Producto de sol y playa para el desarrollo turístico del Municipio Trinidad de Cuba
}

\section{Sun and beach product for tourism development in the Municipality of Trinidad, Cuba}

Nelson García Reinoso ${ }^{1}$, Yomara Quintero Ichazo ${ }^{2}$

Resumen: En Cuba el turismo se ha convertido en uno de los principales motores de la economía. El objetivo de este trabajo fue diseñar un producto de sol y playa que contribuya al desarrollo turístico del municipio Trinidad de Cuba. Se llevó a cabo un estudio bibliográfico para la selección de los métodos a utilizar; se optó por un estudio descriptivo con técnicas de investigación de campo, la observación científica, encuestas y lluvias de ideas. La metodología incluyó un diagnóstico situacional que describió la situación actual de los atractivos y los servicios del destino, que evidenció el gran potencial natural y cultural del municipio. El análisis FODA permitió identificar como problemáticas estratégicas la falta de iniciativa para diseñar nuevos productos turísticos y el incremento de la competencia de otros destinos de sol y playa con similares atractivos naturales. El estudio de mercado permitió identificar las características de la demanda y la oferta para posicionar el producto turístico de sol y playa que se propone en este trabajo, el cual fue concebido de acuerdo a las condiciones que favorezcan el desarrollo turístico del territorio, con una marca turística comercial y la identificación de estrategias para su comercialización.

Palabras claves: Sol y playa, Estudio descriptivo, Iluvia de ideas, FODA, desarrollo turístico.
Abstract: Tourism has become one of the main engines of the Cuban economy. The aim of this work was to design a sun and beach product that contributes to tourism development in the Municipality of Trinidad. A bibliographical study was conducted to select the methods to use; the choice was made for a descriptive study with field study techniques, scientific observation, surveys and brainstorming. The methodology included a situational diagnosis that described the current state of attractions and services of the destination that demonstrated the municipality's great natural and cultural potential. The SWOT analysis identified the lack of initiative to design new tourism products and the increase in competition from other sun and beach destinations with similar natural attractions as strategic issues. The market study identified the characteristics of the supply and demand to position the sun and beach product proposed in this article, which was conceived according to the conditions that promote the territory's tourism development, with a business tourism brand and the identification of strategies for its commercialization.

Key words: Sun and beach, descriptive study, brainstorm, SWOT, tourism development.

\section{(Presentado: 23 de octubre de 2017. Aceptado: 12 de enero de 2018)}

\footnotetext{
1 Master en Gestión Turística, Universidad Central Marta Abreu de Las Villas, Cuba. Docente Investigador, Escuela Superior Politécnica Agropecuaria de Manabí Manuel Félix López, Ecuador.

2 Licenciada en Turismo. Docente Instructora, Universidad Central Martha Abreu de las Villas, Cuba.
} 


\section{INTRODUCCIÓN}

En Cuba el turismo se ha convertido en uno de los principales sectores de la economía, avalado en los últimos años por un crecimiento sostenido mayor que la tasa promedio de la economía nacional, y con perspectiva de mantenerlo a partir de la demanda potencial existente (Castellanos et al., 2014). Este significativo crecimiento e importancia ha provocado un incremento de la competencia entre los destinos turísticos.

Para Espina (2011), el turismo como actividad económica debe incluirse en la línea estratégica del país para su desarrollo que no es más que una recuperación de la dimensión territorial y local como un espacio natural y estratégico para el desarrollo. De igual manera, Perelló (2015) establece que el turismo, como impulsor de la economía, tiene que coadyuvar a la transformación fructífera de un territorio para crear nuevas fuentes de dinamismo que permitan alcanzar objetivos para una nueva concepción de desarrollo sustentable basado en crecer, mejorar la distribución del ingreso, consolidar los procesos democratizadores, adquirir mayor autonomía de las comunidades, crear condiciones que detengan el deterioro ambiental y mejorar la calidad de vida de toda la población.

Los destinos turísticos, según Noguera (2015), están configurados por estructuras urbanísticas, sociales y culturales que persiguen dar satisfacción a las demandas de ocio, negocio y entretenimiento de uno o varios segmentos del mercado turístico. Coincidiendo con Coral (2016) que manifiesta que la puesta en valor de los recursos turísticos-culturales presentes en el medio rural se han convertido en un factor de atracción y diferenciación de los destinos turísticos. Para Garcia et al., (2017) es importante para el desarrollo del turismo comunitario, sustentarse sobre la base de la sostenibilidad en la puesta en valor del patrimonio natural, cultural, social, arquitectónico y gastronómico de la localidad.

El desarrollo local se puede obtener mediante el uso y aprovechamiento eficiente de los recursos locales, muchos de los cuales existen en abundancia en el medio rural, es por eso que las comunidades tienen mucho que ofrecer a sus potenciales visitantes, Echarri et al. (2015) plantea que el desarrollo local es una resultante directa de la capacidad de los actores territoriales y de la sociedad local para estructurarse y movilizarse en base a sus potencialidades, y en su matriz cultural, con vista a definir, explorar sus oportunidades y especificidades en la búsqueda de competitividad en un contexto de rápidas y profundas transformaciones.

La diversificación del producto turístico significa, según Gutiérrez et al. (2001), desde el punto de vista de la oferta, aprovechar al máximo las posibilidades geográficas, económicas, sociales y culturales para llegar a todos los segmentos de mercado y a la mayor cantidad de mercados emisores de turistas. Igualmente Cisneros et al. (2015) consideran que las atracciones son la clave de como rentabilizar el destino, potenciar la innovación y la integración de todos los actores de una localidad en la concepción de un producto turístico integrado siendo la materialización de una ventaja competitiva en el turismo.

El turista de sol y playa tiene como principal motivación el descanso y el esparcimiento, dado que se incluye dentro del turismo de ocio (Martínez, 2001; Rivás, 2004; y Bigné et al., 2007). Este tipo de turismo, considerado también como turismo de costa, según Bigné et al. (2007) comprende "el rango completo de actividades turísticas, de ocio y recreativas que tienen lugar en la zona de costa. Incluye los sectores de alojamiento, restauración, alimentación y segundas residencias; infraestructuras como los comercios y proveedores de actividades de ocio y actividades acuáticas como navegar, ecoturismo marítimo, cruceros, nadar, pescar o bucear, entre otras".

Martínez (2010) afirma que, en el contexto de marketing turístico, debe concebirse al producto como todo aquello, bien sea material o inmaterial, que satisface necesidades y deseos de los turistas, que le resuelve problemas o que disminuye sus costes y desventajas. Tanto de manera preventiva como correctiva y siempre de manera diferenciada a como lo hace la competencia.

El turismo constituye en Cuba una de las principales alternativas para lograr el crecimiento y la diversificación de la economía. Para ello, la política de desarrollo turístico presenta dos aspectos fundamentales vinculados con la utilización del espacio y su conservación como son el ordenamiento del territorio y la protección del medio ambiente, ambos bajo un criterio de sostenibilidad. El turismo por lo general se localiza en Cuba en aquellos sectores donde las 
condiciones naturales e históricas culturales constituyen en sí mismas importantes atractivos (Canales et al., 2011). La inclusión del centro histórico de Trinidad y el Valle de los Ingenios en el listado de bienes materiales protegidos por la UNESCO considerados Patrimonio Cultural de la Humanidad constituye una fortaleza del municipio para el desarrollo de la actividad turística. En Trinidad se conjugan elementos físicos, naturales, históricos y culturales: hermosas playas y límpidos y cristalinos ríos ideales para los bañistas durante todo el año; fondos marinos con barreras coralinas, pecios y peces para la práctica del buceo; las montañas, con paisajes casi vírgenes, en las cuales la riqueza y variedad de la flora y la fauna; cavernas con galerías que sobrepasan centenares de metros y ocultan de la luz del sol impresionantes formaciones espeleológicas; historia rica y enjundiosa de casi cinco siglos, que ha dejado un variado acervo cultural, un conjunto arquitectónico urbano heredado de la conquista y colonización hispana en América que es uno de los mejores conservados del área del Caribe, permiten el desarrollo de las múltiples modalidades del turismo. Canales et al. (2011) considera que en el municipio de Trinidad la Península de Ancón representa el modelo de sol y playa no masificado. Constituye un paraje natural de extraordinario valor por la diversidad de paisajes que ofrece, dado que en los bordes de la bahía encontramos una proliferación de humedales con plantas halófilas. Todo ello contribuye a su atractivo natural dado que esta zona, a pesar del desarrollo turístico alcanzado, mantiene un equilibrio con relación al medio, en el que se conjuga la explotación económica y el respeto a la naturaleza.
La presente investigación tiene como objetivo general diseñar un producto de sol y playa que contribuya al desarrollo turístico del municipio Trinidad de Cuba, donde se integren los atractivos turísticos naturales y culturales que posee y distinguen los cuales deben estructurarse especialmente para satisfacer las demandas turísticas actuales y al mismo tiempo conseguir un reconocimiento turístico para el municipio.

\section{MATERIALES Y MÉTODOS}

La metodología propuesta asociada al diseño de productos turísticos se fundamenta en diferentes instrumentos creados con este fin, concentrado fundamentalmente en los estudios de Machado (2013) sobre "Integración y diseño del producto turístico aplicado a la región central del destino Cuba", Gómez (2014) sobre "Procedimiento metodológico de diseño de productos turísticos para facilitar nuevos emprendimientos”, y Blázquez et al. (2014) sobre "Metodología específica para la creación de producto turístico en torno a vías verdes". De cada metodología se analizaron los elementos que más pertinencia tienen para su aplicación en el objeto de estudio práctico seleccionado, que en este caso se enmarca en el municipio Trinidad de Cuba, para hacerlo lo más adecuado posible a sus características. Resultado de este análisis, se propone estructuró una metodología que responde al desarrollo turístico del municipio con el diseño de un producto de sol y playa, el cual presenta su estructura en la Tabla 1.

\section{Tabla 1. Metodología propuesta para el diseño de un producto turístico de sol y playa}

\begin{tabular}{llll}
\hline Fase & Etapas & Actividades & Técnicas e Instrumentos \\
\hline $\begin{array}{l}\text { 1. Diagnóstico } \\
\text { turístico } \\
\text { situacional }\end{array}$ & $\begin{array}{l}\text { 1. Delimitación } \\
\text { y Caracterización } \\
\text { del área objeto de } \\
\text { estudio }\end{array}$ & $\begin{array}{l}\text { 1. Descripción de la situación actual. } \\
\text { 2. Inventario de los }\end{array}$ & $\begin{array}{l}\text { Investigación de campo, entrevista } \\
\text { dirigida, entrevista libre, } \\
\text { observación científica. }\end{array}$ \\
& $\begin{array}{l}\text { 3. Clasificación de los recursos. } \\
\text { recursos turísticos }\end{array}$ & $\begin{array}{l}\text { 4. Elección de sitios de interés. } \\
\text { 5. Evaluación y jerarquización. }\end{array}$ & Matriz de Potencio turístico del MINTUdes \\
& 6. Estructuración de la matriz FODA. & Matriz FODA \\
& 7. Definición del problema y solución general. & Descriptivo \\
& 3. Estructuración de estrategias. & Fichas de catastro \\
& estratégicóstico & & \\
\hline
\end{tabular}




\begin{tabular}{llll}
\hline $\begin{array}{l}\text { 2. Estudio } \\
\text { de mercado }\end{array}$ & 4. Análisis de la oferta & 1. Identificación de la oferta. & \multicolumn{1}{c}{ Encuestas } \\
& $\begin{array}{ll}\text { 5. Análisis de } \\
\text { la demanda }\end{array}$ & $\begin{array}{l}\text { 2. Expresión matemática para } \\
\text { el cálculo de la muestra. }\end{array}$ & Entrevistas libre \\
& $\begin{array}{l}\text { 3. Análisis de la encuesta. } \\
\text { 4. Perfil del cliente y segmentación } \\
\text { de mercado }\end{array}$ & Matriz de perfil competitivo \\
& 5. Identificación del perfil competitivo costos \\
\hline
\end{tabular}

\begin{tabular}{|c|c|c|}
\hline $\begin{array}{l}\text { 3. Diseño del } \\
\text { producto }\end{array}$ & $\begin{array}{l}\text { 7. Diseño del Producto. } \\
\text { 8. Definición del Precio } \\
\text { 9. Retroalimentación }\end{array}$ & $\begin{array}{l}\text { 1. Desarrollo de acciones que } \\
\text { conducen al diseño del producto. } \\
\text { 2. Confección de fichas de costos. } \\
\text { 3. Establecer índices beneficios. } \\
\text { 4. Seguimiento y chequeo }\end{array}$ \\
\hline
\end{tabular}

4. Comer- 10. Posicionamiento. 1. Análisis de las características cialización del producto

\section{del consumidor.}
2. Estrategias de Posicionamiento
3. Estrategias de comercialización
4. Definir el canal de distribución.
Encuestas
Marketing mix
Observación directa,
benchmarking

canales de distribución

Fuente: Datos de la investigación.

\section{RESULTADOS Y DISCUSIÓN}

Seguidamente se presenta la puesta en práctica del diseño del producto turístico en el municipio Trinidad de Cuba, centrado en el desarrollo del lugar.

\section{Fase 1: Diagnóstico Situacional Actual}

\section{Etapa 1: Delimitación y caracterización del área objeto de estudio}

El municipio Trinidad está situado en la región central de Cuba, al sur de la provincia de Sancti Spíritus. Se extiende desde los $21^{\circ} 05^{\prime}$ hasta los $21^{\circ} 15^{\prime}$ de latitud norte, y entre los $79^{\circ} 45^{\prime}$ y los $80^{\circ} 07^{\prime}$ de longitud oeste. Trinidad limita al norte con los municipios de Fomento provincia de Sancti Spíritus y Manicaragua provincia de Villa Clara; al sur con el Mar Caribe; al oeste con el municipio Cumanayagua provincia de Cienfuegos y al este con el municipio cabecera de la provincia de Sancti Spíritus.

El municipio tiene 62 kilómetros de costas al Mar Caribe, en las cuales se distinguen dos tramos bien diferenciados.
De oeste a este, desde la desembocadura del río Cabagán en el límite con la provincia de Cienfuegos, hasta la Punta de María Aguilar, en la Península del Ancón, existen cerca de 16 kilómetros de costa alta, en ocasiones acantilada, donde predominan los arrecifes o seborucos costeros, sujetos a los procesos abrasivos (Martínez et al 2011).

En este tramo desembocan los ríos Cabagán, Guanayara, Cañas y Guaurabo, los cuales forman barras en sus desembocaduras que en ocasiones interrumpen su comunicación con el mar formando pequeñas playas de arena gruesa y guijarros, que los propios ríos hacen desaparecer durante sus rápidas crecidas cuando llueve en las cercanas montañas donde tienen su nacimiento.

\section{Etapa 2. Inventario de recursos turísticos}

El destino Trinidad posee, a solo $13 \mathrm{~km}$ de la ciudad, las playas de María Aguilar y Ancón las cuales están consideradas como las mejores playas de la costa sur de la isla de Cuba. A 15 millas náuticas de Trinidad se ubican Cayo Blanco y Cayo Machos de Afuera, en el Mar Caribe. El destino posee varios miradores, uno en la Loma del Puerto, otro en La Vigía y el 
último en Topes de Collantes. Desde ellos se pueden observar los bellos paisajes del Valle de los Ingenios y la ciudad. La ciudad se encuentra rodeada por el norte y el noroeste, del macizo montañoso Guamuhaya, el cual posee varias cuevas ubicadas en el Parque Natural de Topes de Collantes. Hacia el este se encuentra el Valle de los Ingenios.

- El Valle de los Ingenios. Fue declarado por la UNESCO Patrimonio Cultural de la Humanidad, conserva vestigios de la vida de los esclavos africanos, así como restos de los principales ingenios que se encontraban en la zona. En su interior se encuentra la Torre de Manaca Iznaga, símbolo de la ciudad por su antigüedad y excelente estado de conservación, ostenta la condición de Monumento Nacional, se eleva hasta más de $40 \mathrm{~m}$ de altura, donde se ubica su cúpula. Desde allí se tiene una vista panorámica del Valle, que es hoy un museo en el que se localizan más de 70 sitios arqueológicos, entre ruinas de fábricas, elementos de maquinaria industrial y objetos de utilidad. Casas de hacendados y almacenes, entre otros, se suman a ese patrimonio.

- El Gran Parque Natural Topes de Collantes. Se encuentra a unos $800 \mathrm{~m}$ sobre el nivel del mar y es un sitio para deleitarse ante la existencia de una pródiga natu- raleza se localiza a $22 \mathrm{~km}$ de la ciudad de Trinidad, a 77 km de Santa Clara, a 80 km de Cienfuegos y a 350 km de La Habana. Las condiciones climáticas allí son excelentes, con parámetros de bienestar ambiental por encima del $60 \%$, tales condiciones determinan las características ecológicas de la región, distinguida por su riqueza de flora y fauna, con un alto nivel de endemismo, atributos estos que dieron lugar a la creación del Gran Parque Natural Topes de Collantes.

La clasificación de los recursos turísticos asociados a la modalidad sol y playa del municipio de Trinidad se encuentran: Ias playas La Boca, María Aguilar, Ancón, Cayo Blanco y Cayo Macho Afuera, siendo estos los de mayor factibilidad en cuanto al acceso para turistas y visitantes. Se tomó como referencia la matriz de potencialidades, junto a la categorización de las fichas de inventario y la observación directa, para de esta forma, priorizar y la elección de los sitios óptimos de mayor interés. La elaboración de la matriz de potencialidades, sustenta la categorización de este destino de sol y playa, con una valoración cualitativa de carácter cultural, ambiental, paisajístico y/o deportivo del sitio, evaluado como (1: moderado, 2: importante, 3: muy importante) Los resultados obtenidos en el municipio de Trinidad de Cuba, se presentan en la Tabla 2.

Tabla 2. Matriz de potencialidades turísticas asociadas a la modalidad de sol y playa.

\begin{tabular}{lllllllllll}
\hline Atractivo y/o recurso & \multicolumn{3}{c}{ Carácter } & \multicolumn{3}{c}{ Atributos } & Total & Potencialidad \\
\hline & C & A & P & D & D & U & A & E & & \\
Playa "La Boca" & 1 & 1 & 2 & 2 & 2 & 3 & 3 & 3 & 17 & Mayor potencialidad \\
Playa "la playa de María Aguilar" & 2 & 1 & 2 & 3 & 3 & 3 & 3 & 3 & 20 & Mayor potencialidad \\
Playa "Cayo Blanco" & 1 & 2 & 2 & 1 & 1 & 2 & 3 & 1 & 13 & Potencialidad emergente \\
Playa "Playa Ancón" & 2 & 3 & 3 & 3 & 4 & 4 & 3 & 3 & 25 & Mayor potencialidad \\
Playa "Cayo Macho Afuera" & 2 & 1 & 2 & 1 & 1 & 1 & 1 & 2 & 11 & Potencialidad emergente \\
\hline
\end{tabular}

Fuente: Datos de la investigación.

Una vez obtenidos los resultados, se prioriza cada sitio de interés de acuerdo a los parámetros de potencialidad. Los sitios con puntuación superior a 15 son los de mayor potencial, mientras que los que obtengan una puntuación inferior al 14 se consideran con potencialidad emergente. En la elaboración del producto turístico de sol y playa se enfatiza en los lugares de mayor relevancia.

\section{Etapa 3: Diagnóstico estratégico}

Para el desarrollo de esta etapa se llevó a cabo un análisis situacional que toma en cuenta los elementos internos y externos de un estudio FODA (Fortalezas, Oportunidades, Debilidades y Amenazas) en el ámbito turístico. El resultado se presenta en la Tabla 3. 


\section{Tabla 3. Análisis FODA turístico en el municipio Trinidad de Cuba}

\section{FORTALEZAS}

1. Incremento de la afluencia de turistas debido al turismo de sol y playa.

2. Existe voluntad política gubernamental de promover el turismo de sol y playa.

3. Adecuada infraestructura y servicios hoteleros y extrahoteleros.

4. Variada oferta de servicios de restauración y excelente gastronomía tradicional.

5. Elevada formación profesional de los trabajadores del turismo.

6. Atractivos culturales y naturales declarados Patrimonio de la Humanidad.

\section{OPORTUNIDADES}

1. Proximidad a mercados masivos, con buena ubicación estratégica cerca de ciudades importantes como Cienfuegos y la Ciudad de Santa Clara.

2. Elevadas potencialidades para el desarrollo turístico de la modalidad de Sol y Playa.

3. Levantamiento de restricciones de viaje a los cubanos-americanos.

4. Alta valoración por la demanda de la calidad cultural, patrimonial y natural del territorio.

5. Valores histórico-patrimoniales que le dan una connotación que marca la diferencia dentro del área.

\section{DEBILIDADES}

1. Carencia de infraestructura aeroportuaria a nivel internacional.

2. Proceso lento y complejo de las inversiones en el destino.

3. Marcada estacionalidad turística.

4. Insuficiente comercialización del destino Trinidad de Cuba.

5. Dependencia de tour operadores europeos.

6. Falta de iniciativa para diseñar nuevos productos turísticos.

\section{AMENAZAS}

1. Impacto de la crisis económica mundial.

2. Escasez de promoción turística a nivel nacional e internacional.

3. Destinos competidores más renovados.

4. Variedad de atractivos turísticos cercanos a la localidad.

5. Mejora de los productos de sol y playa por parte de los mercados competidores.

6. Incremento de la competencia de otros destinos de sol y playa con similares atractivos naturales.
A partir del análisis realizado se determinaron por los autores dos problemáticas estratégicas como las de mayor incidencia actual en el desarrollo de la modalidad turística de sol y playa en el municipio Trinidad de Cuba, siendo uno de estos en el orden interno asociado con la falta de iniciativa para diseñar nuevos productos turísticos y otro problema en el orden externo relacionado con: Incremento de la competencia de otros destinos de sol y playa con similares atractivos naturales. Para dar solución a las problemáticas estratégicas previamente mencionadas y a la vez, aprovechar las elevadas potencialidades para el desarrollo turístico de la modalidad de sol y playa en el cantón, los autores de este trabajo, realizaron la propuesta de diferentes estrategias de reorientación que induzcan a la elaboración y desarrollo de proyectos vinculados con la elaboración de productos turísticos. Dentro de estas se encuentran:
- Implementar acciones para la ordenación y cualificación de los recursos turísticos, orientado a la dinamización del patrimonio trinitario.

- Fortalecer la comunicación, promoción y comercialización para reforzar la imagen del destino y las estrategias de penetración y desarrollo de nuevos productos turísticos.

- Establecer alianzas estratégicas con ciudades como Cienfuegos y Santa Clara.

- Gestionar recursos financieros locales e internacionales que posibiliten un posicionamiento y atraigan las inversiones.

\section{Fase 2: Estudio de Mercado}

Etapa 4: Análisis de la oferta

Según la información más actualizada brindada por la De- 
legación de Turismo del municipio en las ficha de catastros con respecto a la infraestructura turística el destino Trinidad cuenta con numerosos lugares donde el visitante puede alojarse, entre los más destacados se encuentran: Grand Hotel Iberostar Trinidad (40 hab), perteneciente al Grupo Cubanacán se encuentran: Las Cuevas (114 hab), La Villa de Recreo María Dolores (45 hab), Brisas Trinidad del Mar (241 hab), Club Amigo Ancón (279 hab), Club Amigo Costasur, (132 hab) perteneciente a Palmares el Mesón del Regidor (4 hab), del Grupo de Turismo Gaviota S.A el Kurhotel Es- cambray (210 hab), Los Helechos (105 hab) y La Villa Caburní (64 hab). Trinidad reconocida como una de las regiones con mayor densidad de hostales, paladares y cafeterías de Cuba (unos 1.115 en total) según datos de la Oficina del Delegado del Ministro en Sancti-Spíritus (2016).

En el destino Trinidad existen numerosos sitios en los que el visitante puede realizar su restauración, la mayoría de ellos pertenecientes a Palmares. En la Tabla 4 se relacionan los servicios de restauración.

\section{Tabla 4. Servicios de restauración en el municipio Trinidad de Cuba}

\begin{tabular}{clcl}
\hline $\mathbf{N}^{\circ}$ & Restaurante & Plazas & Especialidad \\
\hline 1 & Gourmet del Grand Hotel lberostar Trinidad & 152 & comida internacional \\
2 & El Jigüe & 132 & comida internacional \\
3 & Trinidad Colonial & 100 & comida criolla e internacional \\
4 & Don Antonio. & 106 & comida criolla e internacional \\
5 & Plaza Mayor & 160 & comida criolla e internacional \\
6 & Santa Ana & 200 & comida criolla e internacional \\
7 & Manaca Iznaga & 90 & comida criolla \\
8 & Restaurante Grill Caribe & 60 & comida marinera \\
9 & Mesón del Regidor & 74 & comida internacional \\
10 & Vía Reale & 100 & comida internacional \\
11 & D’prisa & 30 & alimentos ligeros \\
12 & El Mirador & 60 & comida criolla \\
13 & Cafetería Covadonga & 20 & alimentos ligeros \\
14 & Las Begonias & 100 & comida internacional \\
15 & Ruinas de Lleoncy & 80 & comida internacional \\
16 & Taberna La Canchánchara & 100 & alimentos ligeros \\
\hline
\end{tabular}

Fuente: Datos de la investigación.

En el destino Trinidad se encuentran las principales Agencias de Viajes cubanas como Cubatur Centro y Viajes Cubanacán Trinidad. A demás cuenta con una Oficina de Información Turística localizada en la Plaza Santa Ana; y en diversos lugares de la ciudad se encuentran mapas en los que se muestran los principales sitios de atracción turística. El destino posee un variado número de actividades que permiten satisfacer los más variados gustos y necesidades de los clientes; aunque no se puede dejar de plantear que en este aspecto aún se puede mejorar en gran medida, ya que el destino posee varios atractivos que no son plenamente aprovechados, tales como el Valle de los Ingenios.

\section{Etapa 5: Análisis de la demanda}

El turismo internacional al cierre de agosto de 2016, registro un crecimiento del $12 \%$ al arribar al país 2.720 .728 visitantes, que significaron 290.490 más que en igual período del año anterior. En el mes de agosto se recibieron 266.183 visitantes, que representaron un $10,8 \%$ más que en igual mes de 2015 según la Oficina Nacional de Estadística e Información (ONEI), lo que equivale a 25.969 más que en el mismo periodo del año anterior. Canadá resultó ser el país mayor emisor de viajeros a la isla en el año 2015, con un total de 1.300.092, lo que supuso un crecimiento del $10,6 \%$ seguido en orden cuantitativo por Alemania, Reino Unido, Francia, Italia, España, México, Venezuela, Argentina, Chile, Rusia, Holanda, Suiza, China, Colombia, Polonia, Perú y otros países. La mayor cantidad de turistas procedentes de Latinoamérica correspondió a México y Venezuela, con 105.406 y 95.123 , respectivamente; secundados por Argentina, con 85.172; y Chile, que aportó 49.194 viajeros. 
El aumento de visitantes en 2016 conllevará una presumible demanda de alojamientos para Cuba que en la actualidad dispone de 62.000 habitaciones, de las cuales más del $60 \%$ están bajo contrato de comercialización extranjera y un $16 \%$ son operadas por empresas mixtas. Por ello, las autoridades del sector han anunciado sus planes para ampliar hasta 85.000 las habitaciones en 2020, incluidas más de 13.600 previstas para abrir en "polos de sol y playa" durante 2016. Estadísticas de la Delegación del MINTUR en Trinidad plantean que los principales emisores de turistas hacia el territorio y que se han alojado en hoteles son: Alemania, Canadá, Rusia y Francia por ese orden y las principales características de la demanda se muestran en la Tabla 5.

\section{Tabla 5. Principales características de la demanda del destino Trinidad de Cuba}

\begin{tabular}{|c|c|c|}
\hline $\mathbf{N}^{\circ}$ & País & Características \\
\hline 1 & Canadá & $\begin{array}{l}\text { - Los viajes son considerados la primera fuente de recreación. } \\
\text { - Sus gastos son muy planificados, solo compran lo necesario. } \\
\text { - Gustan de las actividades recreativas, la playa, la tranquilidad y la seguridad. } \\
\text { Aman la naturaleza y sienten un profundo respeto hacia ella. }\end{array}$ \\
\hline 2 & Reino Unido & $\begin{array}{l}\text { - El turismo de sol y playa tiene mayor importancia para los británicos } \\
\text { que para otros europeos. } \\
\text { - Son personas con alto nivel cultural y educacional. }\end{array}$ \\
\hline 3 & Italia & $\begin{array}{l}\text { - Buscan fundamentalmente ofertas que combinen la ciudad con la playa, la } \\
\text { ecología y actividades sobre la cultura nacional, con la historia y el pueblo. } \\
\text { - Otorgan gran valor a la cultura del servicio, así como prefieren visitar lugares } \\
\text { de interés cultural. }\end{array}$ \\
\hline 4 & España & $\begin{array}{l}\text { - Prefieren la combinación de estancia y circuitos. } \\
\text { - Las motivaciones principales en el deseo de viajar a Cuba son: el pueblo, } \\
\text { el clima, las playas, curiosidad, cultura e interés sociopolítico. }\end{array}$ \\
\hline 5 & Alemania & $\begin{array}{l}\text { - Buscan en sus vacaciones buen clima, sol, bellezas naturales, ambiente limpio } \\
\text { e higiénico, lugares seguros, con ausencia de guerras y disturbios sociales, bañarse } \\
\text { en playas o piscinas, posibilidades para excursiones y ofertas culturales. }\end{array}$ \\
\hline 6 & Francia & $\begin{array}{l}\text { - Los programas con ofertas culturales, históricas, así como los que propician el } \\
\text { disfrute de la naturaleza tienen una considerable demanda entre los } \\
\text { vacacionistas franceses. } \\
\text { - Los hoteles, así como los niveles de precios de los diferentes productos, los } \\
\text { guías y la seguridad que Cuba ofrece al turista satisfacen sus expectativas y exigencias, } \\
\text { - Tienen entre los principales motivos de viajes: el clima y las playas. } \\
\text { Prefieren programas que combinen estancias y recorridos. }\end{array}$ \\
\hline 7 & Federación Rusa & $\begin{array}{l}\text { - Buscan el sol y la playa combinando su estancia con excursiones de carácter } \\
\text { cultural, natural o urbano, de las cuales son grandes consumidores. }\end{array}$ \\
\hline
\end{tabular}

Fuente: Elaboración propia en base a a Ministerio del Turismo (2016).

\section{Etapa 6: Análisis de la competencia}

Se llevó a cabo la realización de una matriz del perfil competitivo, tomando como referencia los principales y más próximos mercados competidores directos de las playas de Trinidad de Cuba, que en este caso son el municipio de Cienfuegos, cabecera de la provincia homónima, y Caibarién de la provincia Santa Clara. Aquí solamente se consideraron aspectos relacionados con la modalidad de sol y playa, clasificados en una escala máxima de 4 pun- tos. Los resultados comparativos se resumen en la Tabla 6. De acuerdo a los resultados obtenidos anteriormente, la principal competencia para el municipio Trinidad de Cuba en esta modalidad lo constituye el municipio de Caibarién con sus playas de la cayería del Norte de Villa Clara. Derivado de este resultado, en los factores que deben trabajarse para su mejora está la limpieza de las playas y promoción turística. 
Tabla 6. Evaluación del perfil competitivo del municipio de Trinidad de Cuba y sus competidores directos

\begin{tabular}{lccccccc}
\hline \multirow{2}{*}{ Factores claves de éxito } & Criterio & \multicolumn{2}{c}{ Trinidad de Cuba } & \multicolumn{2}{c}{ Cienfuegos } & \multicolumn{2}{c}{ Caibarién } \\
\cline { 2 - 7 } & ponderado & Clasif. & Resultado & Clasif. & Resultado & Clasif. & Resultado \\
\hline Entorno natural & 0,10 & 4 & 0,40 & 3 & 0,20 & 4 & 0,40 \\
Limpieza playas & 0,15 & 3 & 0,45 & 3 & 0,45 & 4 & 0,60 \\
Promoción turística & 0,10 & 3 & 0,30 & 3 & 0,30 & 4 & 0,40 \\
Demanda turística & 0,20 & 4 & 0,80 & 3 & 0,60 & 3 & 0,60 \\
Oferta turística & 0,10 & 4 & 0,40 & 3 & 0,30 & 4 & 0,40 \\
Actividades recreativas & 0,10 & 4 & 0,40 & 3 & 0,30 & 3 & 0,30 \\
Accesibilidad & 0,15 & 4 & 0,60 & 3 & 0,45 & 3 & 0,45 \\
Seguridad & 0,10 & 4 & 0,40 & 4 & 0,40 & 4 & 0,40 \\
\hline Resultado total ponderado & $\mathbf{1 , 0 0}$ & \multicolumn{7}{c}{$\mathbf{3 , 7 5}$} & & $\mathbf{3 , 0 0}$ & & $\mathbf{3 , 5 5}$ \\
\hline
\end{tabular}

Fuente: Elaboración propia en base a Ministerio del Turismo (2016).

\section{Fase 3: Diseño del Producto}

\section{Etapa 7: Diseño del producto}

Se realizaron salidas de verificación a los lugares de interés turístico priorizados en el estudio del mercado, se establecieron los tiempos y distancias pertinentes entre cada uno de los atractivos, se realizó una georreferenciación y toma de fotos; con la identificación de la infraestructura, facilidades y equipamientos de cada uno de los recorridos. Se llevó a cabo el diseño de una ruta que tomó en consideración los atractivos de mayor potencialidad anteriormente identificados en la matriz de potencialidades de la Tabla 2. De la misma forma se tomó en cuenta el resultado del estudio de mercado, que evidencia un interés por los visitantes en las playas del municipio Trinidad de Cuba, elementos que expresan este sitio como un destino turístico de sol y playa. Para la ruta propuesta se elaboró un mapa gráfico fundamentado por los parámetros como la jerarquía de atractivos turísticos, servicios y actividades ofrecidas y la accesibilidad hacia cada uno de ellos. La ruta diseñada se muestra en la Figura 1.

Figura 1. Diseño de la ruta turística de sol y playa del municipio Trinidad de Cuba.

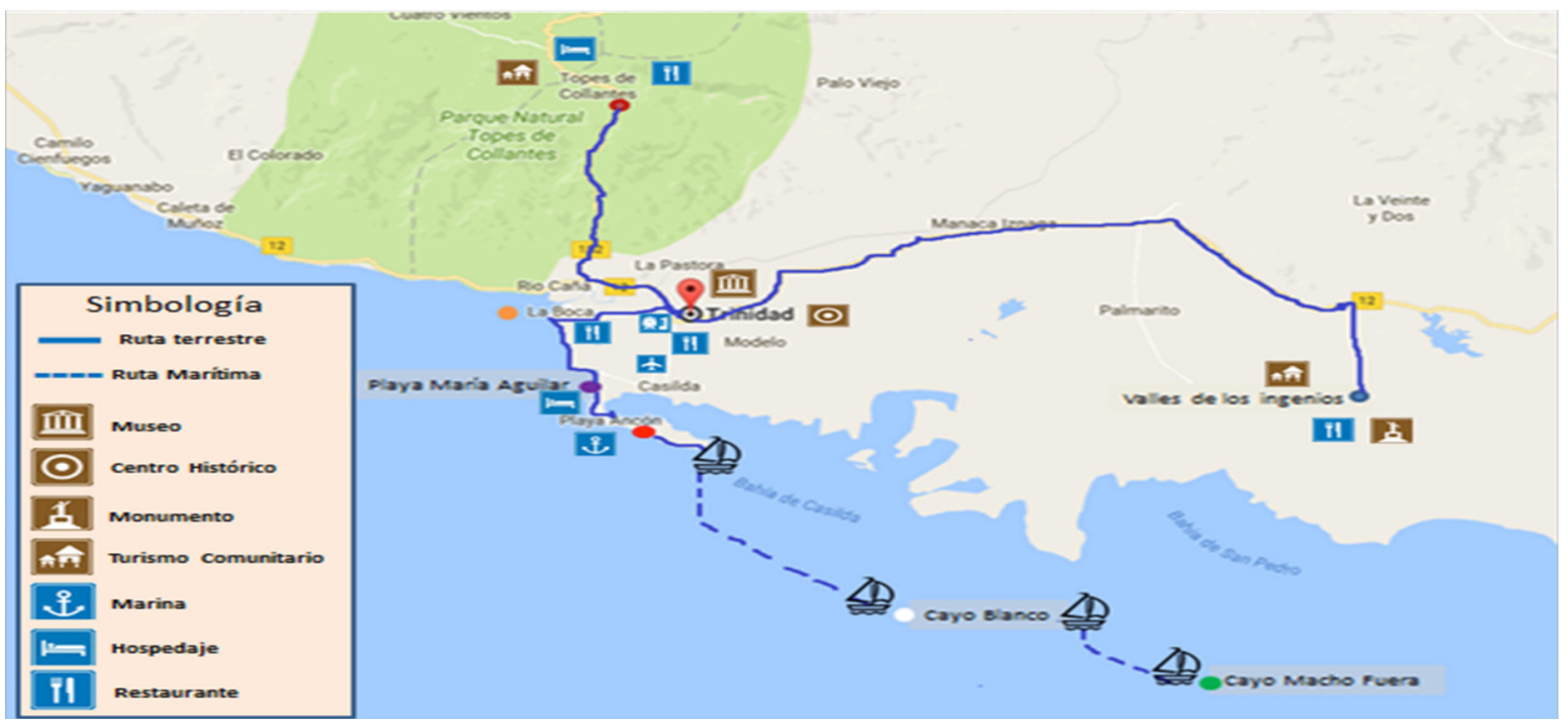

Fuente: Datos de la investigación. 
El diseño del producto turístico se realizó tomando en consideración lo propuesto por Machado (2010). En este se consideraron cinco atractivos turísticos de la línea de sol y playa y se valoró positivamente la inclusión de otros dos atractivos que responden a la línea del ecoturismo y el turismo comunitario, como un complemento de variedad, necesario y a tono con la propuesta de la ruta. Cada uno de los atractivos se describe en la Tabla 7.

Tabla 7. Descripción de los atractivos en la ruta turística.

\begin{tabular}{lll}
\hline \multicolumn{1}{c}{ Atractivos } & \multicolumn{1}{c}{ Descripción } & \multicolumn{1}{c}{$\begin{array}{c}\text { Servicios } \\
\text { turísticos }\end{array}$} \\
\hline Parque Natural & Se encuentra localizado a solo 20 km de Trinidad, es un extraordinario & Restaurantes, \\
Topes de & paisaje natural de $200 \mathrm{~km}^{2}$, insertado en el grupo montañoso de & hoteles, \\
Collantes & Guamuhaya. Este ecosistema montañoso cuenta con imponentes & cabañas, \\
(ecoturismo & elevaciones, una exuberante vegetación, un alto endemismo de la flora y & guianza, \\
y turismo & la fauna, innumerables sistemas cavernarios, bellos paisajes, numerosos & senderismo. \\
comunitario) & ríos y riachuelos que forman saltos y pozas naturales, está compuesto & \\
& por 4 Parques Naturales: Guanayara, Codina, Altiplano Topes de Collantes & \\
& y El Cubano. & \\
\hline
\end{tabular}

Este balneario a $5 \mathrm{~km}$ de la ciudad de Trinidad de pequeña cala rocosa,

Playa "La Boca" (sol y playa) escondida y lejos de los habituales circuitos turísticos de la zona de Trinidad, se abre al mar Caribe justo debajo de las imponentes montañas del Escambray, de las que se puede tener unas vistas maravillosas, es un lugar que ofrece un entorno tranquilo y encantador rodeados de la naturaleza y de la práctica de deportes acuáticos y áreas magnificas donde bucear.
Restaurantes, hoteles, buceo.
Se encuentra localizado a $25 \mathrm{~km}$, ocupa una extensa planicie de forma triangular que abarca alrededor de $250 \mathrm{~km} 2$ y comprende en su interior

Valle de los Ingenios (turismo comunitario)

Playa "la playa de María Aguilar" (sol y playa) los valles de San Luis, Agabama Méyer y Santa Rosa, además de la llanura costera del sur, delta del río Manatí, fue reconocido por la UNESCO como Patrimonio de la Humanidad en el año 1988. El valle cuenta con 65 sitios arqueológicos, incluidas 13 casas haciendas, algunas de la cuales cuentan aún con sus calderas, torres, sistemas industriales de la época y vestigios propios de la producción azucarera, de los siglos del XVIII al XIX.
Restaurantes, artesanías.
A $13 \mathrm{Km}$ de la ciudad se pueden encontrar las playas de María Aguilar, que brindan al visitante $4 \mathrm{~km}$ de arenas blancas para su disfrute. Esta tranquila playa de aguas caribeñas se encuentra en la misma península de Ancón y sus excepcionales fondos transparentes la convierten en un lugar ideal para la práctica de deportes acuáticos como el buceo en superficie o el submarinismo.
Restaurantes, hoteles, buceo.
Considerada la mejor playa de todo el sur de Cuba y está situada a 15 km de la villa de Trinidad llama la atención por su interesante vegetación

Playa "Playa Ancón" (sol y playa) de pinos y palmeras y las imponentes montañas que la abrazan y que forman parte de la bonita sierra del Escambray, destacadas por sus finas y blancas arenas; así como por la pureza y claridad de sus aguas y fondos marinos. En esa zona se ubican varias instalaciones hoteleras, como son: el Hotel Brisas Trinidad del Mar, el Hotel Ancón y el Hotel Costa Sur.
Restaurantes, hoteles, bares, buceo. 


\begin{tabular}{lrr} 
Atractivos & Descripción & $\begin{array}{l}\text { Servicios } \\
\text { turísticos }\end{array}$ \\
\hline
\end{tabular}

\begin{tabular}{lll}
\hline & Se oferta la práctica de buceo en 23 puntos de inmersión y & \\
& servicios de vida a bordo en los Jardines de la Reina, servicios de & \\
Pltraque, fondeo, agua, electricidad, comisaría, combustibles, & Restaurantes, \\
(sol y playa) & baños y duchas, además cuenta con el bar restaurante "Ranchón & buceo, pesca. \\
& de la Marina”. En los fondos marinos de esta zona que se distingue & \\
& por ser arenosa, sobresalen parches coralinos y camellones que & \\
& alcanzan los 5 m de altura, así como túneles y otros accidentes \\
& geográficos.
\end{tabular}

La marina de la Península de Ancón brinda las de paseos en yate a los cayos Blanco y Macho Afuera, pesca a fondo, así como práctica Playa "Cayo de buceo, el área presenta canales estrechos que en algunas parMacho Afuera" tes formas túneles. La fauna es muy típica, notable por las largas (sol y playa) esponjas de diferentes colores y tamaños, más de 40 especies de

Restaurantes, buceo, pesca. corales, incluyendo paredes con bosques de coral negro.

Fuente: Datos de la investigación.

En la definición del nombre comercial del producto, se sintetizaron ideas y características referentes a las actividades para cumplir las expectativas del visitante. El producto se nombró: "Cerca del mar y del monte", tomando en cuenta las características del territorio, asociado a un sitio de abundantes atractivos naturales, y relacionado con las características del turismo de sol y playa, con el propósito de garantizar el bienestar en un paraíso turístico rodeado de riquezas naturales y culturales.

\section{Etapa 8: Definición del precio}

En esta etapa se tomó en cuenta el criterio de los consumidores y en este caso, se llevó a cabo la aplicación de una encuesta, que recogió opiniones de visitantes potenciales, derivándose una moda estadística, de pago mínimo de $\$ 150,00$ dólares por pax en una oferta que incluya todos los servicios en el producto turístico propuesto exceptuando el alojamiento. Otro resultado derivado fueron las características del precio:

- Accesible a todos los niveles sociales.

- Expresa eficacia del servicio a prestar y a la vez la rentabilidad a obtener.

\section{Etapa 9: Retroalimentación}

En esta etapa, los registros de satisfacción del cliente constituyen el principal indicador de retroalimentación del producto turístico de sol y playa para el municipio Trinidad de Cuba diseñado comprobado mediante encuestas de satisfacción. Además se implementa un libro de registro de quejas y sugerencias, mediante las cuales se podrán tomar decisiones correctivas para el bienestar del producto. Se verifica el cumplimiento de los itinerarios y servicios ofrecidos en el producto y se registran y evalúan los resultados de los recorridos con el objetivo de garantizar el mantenimiento y mejoramiento del producto.

\section{Fase 4: Gestión de la Comercialización del Producto}

\section{Etapa 10. Posicionamiento}

Para facilitar el posicionamiento del producto se deben aplicar estrategias de forma que su estructura de diseño sea óptima y aceptada; en este caso, clientes apasionados por disfrutar de los beneficios y atracciones de la modalidad de sol y playa en el municipio Trinidad de Cuba, para su lanzamiento es de gran importancia tener en cuenta las características de los clientes para determinar el segmento del mercado. La principal estrategia de posicionamiento fue el diseño de una marca turística, que se presenta en la Tabla 8, para la asimilación del producto en el consumidor y como ente promocional de las características que brinda este producto y sus diferencias con otros, mostrando una imagen acertada. 
Tabla 8. Marca turística del producto diseñado

Logotipo
Los recursos culturales del destino Trinidad se pueden considerar como muy valiosos, de-
clarado el Casco Histórico de la ciudad conjuntamente con el Valle de los Ingenios, como
Patrimonio Mundial de la Humanidad por la UNESCO, privilegiado por la riqueza y variedad
de sus recursos naturales. Posee el Parque Natural Topes de Collantes, de extraordinario
valor natural y que posibilita el desarrollo de numerosos programas naturales y ecoturís-
ticos, los cayos cercanos y las hermosas playas hacen que el destino provoque una gran
atracción para las actividades turísticas.

Fuente: Datos de la investigación.

Este producto turístico de sol y playa propuesto busca satisfacer las necesidades y expectativas de los turistas, adecuado a sus preferencias, gustos y características, con el fin de brindar un buen servicio y el uso responsable de las actividades a realizarse. El mismo cuenta con características de ubicación en un medio con características únicas de belleza, singularidad, con ambiente agradable para sus visitantes. Se prestan principalmente servicios de: alojamiento, restauración, guianza a sitios naturales, deportes acuáticos, buceo y convivencia cultural y se propone diferentes estrategias comerciales.

\section{Estrategias para el producto}

- Diversificar la oferta natural a partir de las facilidades y las potencialidades locales.

- Visita a lugares como Parque Natural Topes de Collantes y Valle de los Ingenios, complemento en la variedad del producto.

\section{Estrategias para el precio}

- Acceso a facilidades financieras.

- Establecer precios acorde al estudio de mercado realizado y los valores referenciales del mercado, determinándose facilidades de pago.

\section{Estrategias para la plaza}

- Activación de canales de comercialización apropiados

- Determinar temporadas de difusión del producto.

\section{Estrategias para la promoción}

- Redefinición del producto turístico así como de la es trategia de comercialización y promoción del destino.

- Brindar paquetes a menor costo en temporadas bajas. Recompensación de participación, comunicar beneficios de la oferta.
- Enfatizar en la marca creada de la oferta en ferias comerciales.

Etapa 11. Selección de los canales de distribución Se tomaran como referente en la comercialización del producto turístico de sol y playa los canales de distribución formado por las agencias de viajes y touroperadores que operaban en el municipio con los mercados seleccionados y se lanzó a través de las mismos la comercialización del producto. Se realizan plegables, sueltos y una página Web interactiva que promueva la ruta mediante la presentación de los lugares de interés turísticos de acuerdo al turismo de sol y playa, itinerario de recorrido, actividades y facilidades de manera tan que los clientes tengan acceso a la mismos y puedan conocer los detalles de la excursión y las excelentes atractivos naturales y culturales que ofrece el lugar.

\section{CONCLUSIONES}

El diagnóstico situacional realizado evidencia que el municipio Trinidad de Cuba posee variados y excelentes atractivos naturales y culturales, donde destacan sus demandadas playas, ideales para la creación de un producto turístico de sol y playa. El análisis estratégico permitió identificar como problemáticas la falta de iniciativa para diseñar nuevos productos turísticos y el incremento de la competencia de otros destinos de sol y playa con similares atractivos naturales. Las estrategias de reorientación identificadas se dirigen a fortalecer la comunicación, promoción y comercialización para reforzar la imagen del destino y las estrategias de penetración y desarrollo de nuevos productos turísticos. Se diseñó un producto turístico de sol y playa, que toma en cuenta, el aprovechamien- 
to de los atractivos turísticos asociados a esta modalidad en el municipio Trinidad de Cuba, acorde a las necesidades, intereses y expectativas del turista actual. La comercialización del producto de sol y playa propuesto para el municipio Trinidad de Cuba tomó en cuenta el posicionamiento con el diseño de una marca turística y la definición de varias estrategias de marketing-mix, que facilitan su gestión y desarrollo eficaz y de esta manera contribuir al desarrollo turístico del territorio.

\section{REFERENCIAS}

Bigné, E., Sánchez, I., Currás, R. (2007). El papel de la imagen del destino en la valoración y comportamiento postcompra del turista de sol y playa. Papers de Turisme 42, 57-73.

Blázquez, J., Sarrión, J. (2014). Metodología específica para la creación de producto turístico en torno a vías verdes. España. Consultado el 20 de marzo de 2016. Disponible en http://www.viasverdes. com/greenwaysproduct/pdf/Metodologia-creacion-producto-turistico.pdf

Canales, G., Sabariegos, J. (2011). Trinidad, producto turístico integral y sostenible en Cuba. Cuadernos de Turismo 27, 95-114.

Castellanos, C.A., Hernández, Y., Castellanos, J.R., Campos, L.M. (2014). La competitividad del destino turístico Villa Clara, Cuba: Identificación de sus factores determinantes mediante análisis estructural (MIC-MAC). Estudios y Perspectivas en Turismo 23, 2, 250-277.

Cisneros, L., García, Y. (2015). Contribución del turismo al desarrollo local en Cuba desde la perspectiva de la gestión del destino. Revista Científica Ecociencia Contribución 2, 3, 1-21.

Echarri, M., Bulnes, D. (2015). Diseño preliminar del plan de desarrollo turístico para municipios seleccionados de la provincia Mayabeque, Cuba (2015-2020). Ecociencia 2, 6, 1-30.

Espina, M. (2010). Apuntes sobre el concepto de desarrollo y su dimensión territorial. Consultado el 20 de marzo del 2016. Disponible en http://cvirtual. filosofia.cu/subcomunidades/gemas/sesion-cientifica-28-05-2013-

García, N., Doumet, N.Y. (2017). El producto turístico comunitario como estrategia para diversificar las economías locales del cantón Bolívar, provincia de Manabí, Ecuador. Revista Interamericana de Ambiente y Turismo 13, 1, 105-116.

Gómez, G. (2014). Procedimiento metodológico de diseño de productos turísticos para facilitar nuevos emprendimientos. Consultado el 20 de marzo del 2016. Disponible en http://dspace.ups.edu.ec/ bitstream/123456789/9624/1/Procedimiento\%20metodol\%C3\%B3gico\%20de\%3\%ADsticos\%20para\%20facilitar\%20nuevos\%20emprendimientos.pdf

Gutiérrez, O., Gancedo, N. (2001). Estrategia de desarrollo del turismo en Cuba: resultados, retos y perspectivas. Investigación Turística, 1-20.

Machado, E.L. (2013). Integración y diseño del producto turístico. Aplicado a la región central del destino Cuba. GeoGraphos 4, 35, 69-92.

Martínez, J.A. (2010). Marketing turístico y gestión del producto. Revista Turismo y Desarrollo 3, 8.

Martínez, R. (2001). Aproximación al estudio del sector turístico almeriense: análisis de la oferta y de la demanda en temporada alta. Cuadernos de Turismo 7, 81-91.

Moral, M. (2016). La puesta en valor de un recurso turístico cultural sostenible en el medio rural: El caso de las Vías Verdes en España. Revista Interamericana de Ambiente y Turismo 12, 2, 161-175.

Noguera, J., Ferrandis, A., Madrid, V. (2015). Comportamiento comercial y hábitos de consumo de los turistas en un destino maduro de sol y playa: EI caso de Cullera. Investigaciones Turísticas 10, 90-116.

Perelló, J. L. (2015): Turismo y desarrollo territorial en el modelo económico y social de Cuba. Revista Turismo y Desarrollo 18.

Rivas, J. (2004). Estructura y Economía del Mercado Turístico. España: Septem Ediciones. 